\title{
Genotyping and Tetracycline Resistance of Campylobacter jejuni \& Campylobacter coli Isolated from Broiler and Human Fecal Samples
}

\author{
A. Wahdan ${ }^{1}$, Wafaa, M. M. H. ${ }^{2}$, A. A. A. Mekky ${ }^{3}$ and, M. E. Enany ${ }^{1}$ \\ ${ }^{1}$ Dept.of bacteriology, immunology and mycology, Fac. of Vet. Med. Suez \\ Canal Univ. Ismailia, Egypt. ${ }^{2}$ Referencelaboratory for veterinary quality \\ control on poultry production, animal health research institute, Dokki, Giza, \\ Egypt. ${ }^{3}$ Referencelaboratory for veterinary quality control on poultry \\ production, animal health research institute, Ismailia, Egypt
}

\begin{abstract}
:
Campylobacteriosis is one of the main common food borne illnesses all over the world causing gastroenteritis in human. So, this study aimed to make genotyping of Campylobacter spp. isolated from fecal samples of both broiler and human with detection of tetracycline resistance strains. A total of 100 Campylobacter spp. previously identified and confirmed by presence of $23 \mathrm{~S} r R N A$ gene from broiler and human fecal samples (50 of each) were subjected to duplex conventional PCR for detection of mapA gene which specific for $C$. jejuni and ceuE gene for $C$. coli. Tweenty randomly selected Campylobacter strains (10 from C. coli and 10 from C. jejuni) were examined for presence of TetO gene which responsible for tetracycline resistance. Results revealed that, the total percentages of C. coli and C. jejuni were $76 \%$ and $24 \%$ respectively. C. jejuni was $14 \%$ while $C$. coli was $86 \%$ in fecal samples collected from broiler, while fecal samples collected from human, the percentage of $C$. jejuni was $34 \%$ while $C$. coli was $66 \%$. All 20 recovered strains showed completely resistance to tetracycline with percentage $100 \%$, which is considered the first record in Ismailia, Egypt. This study gives insight about the importance of continuous survey of Campylobacter strains with great attention to developing of newly antimicrobial resistance strains.
\end{abstract}

Keywords: Campylobacter, ceuE gene, mapA gene, TetO gene, Broilers, Human, PCR

\section{Introduction:}

Campylobacter is considered to be the most common bacterial cause of human gastroenteritis in the world (WHO, 2002). Consumption of undercooked poultry products or the mishandling of raw poultry products is the most likely source of exposure to Campylobacter (Bernadette et al., 2012). 
Broiler chickens are frequently asymptomatic carriers of $C$. jejuni and $C$. coli and the organisms are common contaminants of processed broiler carcasses. During the slaughtering and processing, poultry can become contaminated with Campylobacter from their intestinal contents (Burgos et al., 2017).

The source of contamination has been attributed to the entry of Campylobacter into the processing plant in the intestinal tracts of asymptomatic broilers and the subsequent contamination of equipment and cross-contamination during processing (Park, 2002)

The most important 2 types of Campylobacter spp. isolated from fecal samples in Portugal are C. coli and $C$.jejuni. $C$. jejuni is now the most widely recognized antecedent cause of Guillain-Barre' syndrome, an acute paralytic disease of the peripheral nervous system $(\boldsymbol{C D C}$, 2013).

The incidence of Campylobacter was higher in case of fecal swab, followed by fecal samples then duodenum samples, while bile samples were negative. (Persson and Olsen 2005).

C. coli showed higher resistance against antibiotics than $C$. jejuni. $C$. jejuni showed high resistance against ciprofloxacin and nalidixic acid (Schwan, 2010). Emerging of newly resistant Campylobacter isolates to antibiotics continuously occurs, so continuous survey of Campylobacter resistance should be under research.

\section{Materials and Methods:}

\section{Samples}

A total of 100 Campylobacter spp. previously isolated selective enrichment method using Bolton Broth and CCDA agar and well identified phenotypically. And genetically confirmed by detection of 23SrRNA gene isolated from broiler and human fecal samples (50 of each) were subjected to duplex conventional PCR for genotyping and detection of Campylobacter tetracycline resistant strains at the Reference Laboratory for Veterinary Quality Control on Poultry Production (RLQP), Ismailia branch, Egypt.

\section{Extraction of DNA}

According to QIAamp DNA mini kit instructions (Catalogue no. 51304). The QIAamp DNA Mini Kit provides silica-membrane-based nucleic acid purification from different types of samples according to (Ezzat et al., 2018). The spincolumn procedure does not require mechanical homogenization, so total hands-on preparation time is only 20 minutes.

Genotyping of Campylobacter spp. using duplex Conventional PCR reaction

PCR Master Mix for cPCR was prepared according to Emerald Amp GT PCR mastermix (Takara) Code No. RR310Akit as shown in Table (1). Primers were supplied from Metabion (Germany), they have specific sequence and amplify specific products as shown in Table (3) according to (Eunju and Lee 
2009). Cycling conditions of the primers during cPCR shown in Table (4).

\section{Detection of Campylobacter} resistant strains

About 20 randomly selected Campylobacter strains (10 strains from $C$. coli and 10 strains from $C$. jejuni) from both broiler and human were tested for detection of TetO gene which responsible for Campylobacter tetracycline resistance as the most common used antibiotic. PCR Master Mix for cPCR was prepared according to Emerald Amp GT PCR mastermix (Takara) Code No.RR310Akit as shown in Table (2). Primers were supplied from Metabion (Germany), they have specific sequence and amplify specific products as shown in Table (3) according to (Gibreel et al., 2004). Cycling conditions of the primers during cPCR shown in Table (4). Electrophoresis grade agarose $(1.5 \mathrm{~g})$ was prepared in 100 $\mathrm{ml}$ TBE buffer in a sterile flask, it was heated in microwave to dissolve all granules with agitation, and allowed to cool at $70^{\circ} \mathrm{C}$, then $0.5 \mu \mathrm{g} / \mathrm{ml}$ ethidium bromide was added and mixed thoroughly. The gel was photographed by a gel documentation system and the data was analyzed through computer software.

\section{Results:}

Results shown in Table (5) revealed that the total percentage of $C$. jejuni isolated from both broiler and human was $24 \%$ while $C$. coli was $76 \%$. These results indicated that C. coli were represented in high percentage than $C$. jejuni.

The percentage of $C$. jejuni was 14 $\%$ while $C$. coli was $86 \%$. While fecal samples collected from human, the percentage of $C$. jejuni was $34 \%$ while $C$. coli was $66 \%$.

Photos (1) \& (2) illustrated the genotyping of campylobacter strains isolated from broiler and human for detection of mapA gene for $C$. jejuni at $589 \mathrm{bp}$ fragment and ceuE gene for $C$. coli at $462 \mathrm{bp}$ fragment.

Regarding to sensitivity of randomly selected 20 campylobacter strains $(10$ from C.coli and 10 from C.jejuni) from both broiler and human fecal samples. Photo (3) showed that, all tested strains were resistant to tetracyclines with a percentage $100 \%$ 
Table (1) Preparation of duplex PCR Master Mix for genotyping of campylobacter spp.

\begin{tabular}{|c|c|}
\hline Component & Volume/reaction \\
\hline Emerald Amp GT PCR mastermix (2x premix) & $25 \mu l$ \\
\hline PCR grade water & $15 \mu l$ \\
\hline Forward primer(20 pmol) & $1 \mu l$ each (2) \\
\hline Reverse primer (20 pmol) & $1 \mu l$ each (2) \\
\hline Template DNA & $6 \mu l$ \\
\hline Total & $50 \mu l$ \\
\hline
\end{tabular}

Table (2) Preparation of PCR Master Mix for tetracycline resistance gene:

\begin{tabular}{|c|c|}
\hline Component & Volume/reaction \\
\hline Emerald Amp GT PCR mastermix (2x premix) & $12.5 \mu l$ \\
\hline PCR grade water & $4.5 \mu l$ \\
\hline Forward primer(20 pmol) & $1 \mu l$ \\
\hline Reverse primer (20 pmol) & $1 \mu l$ \\
\hline Template DNA & $6 \mu l$ \\
\hline Total & $25 \mu l$ \\
\hline
\end{tabular}

Table (3): primers sequences for ceuE, mapA and TetO genes.

\begin{tabular}{|c|c|c|c|c|}
\hline $\begin{array}{l}\text { Target } \\
\text { gene }\end{array}$ & specificity & $\begin{array}{l}\text { Primer sequence } \\
\qquad\left(5^{\prime}-3^{\prime}\right)\end{array}$ & $\begin{array}{l}\text { Length of } \\
\text { amplified } \\
\text { product } \\
\text { (bp) }\end{array}$ & Reference \\
\hline \multirow{2}{*}{$c e u E$} & \multirow{2}{*}{ C. coli } & AAT TGA AAA TTG CTC CAA CTA TG & \multirow{2}{*}{462} & \multirow{4}{*}{$\begin{array}{c}\text { Eunju } \\
\text { and Lee, } \\
2009\end{array}$} \\
\hline & & TGA TTT TAT TAT TTG TAG CAG CG & & \\
\hline \multirow{2}{*}{ тарА } & \multirow{2}{*}{ C. jejuni } & CTA TTT TAT TTT TGA GTG CTT GTG & \multirow{2}{*}{589} & \\
\hline & & GCT TTA TTT GCC ATT TGT TTT ATT A & & \\
\hline \multirow{2}{*}{$\underline{\text { TetO}}$} & \multirow{2}{*}{$\begin{array}{l}\text { Tetracycline } \\
\text { resistance }\end{array}$} & GGCGTTTTGTTTATGTGCG & \multirow{2}{*}{559} & \multirow{2}{*}{$\begin{array}{l}\text { Gibreelet } \\
\text { al., } 2004\end{array}$} \\
\hline & & ATGGACAACCCGACAGAAGC & & \\
\hline
\end{tabular}

Table (4) Cycling conditions of the primers during cPCR.

\begin{tabular}{|c|c|c|c|c|c|c|}
\hline Gene & $\begin{array}{c}\text { Primary } \\
\text { denaturation }\end{array}$ & $\begin{array}{c}\text { Secondary } \\
\text { denaturation }\end{array}$ & Annealing & Extension & $\begin{array}{c}\text { No. of } \\
\text { cycles }\end{array}$ & $\begin{array}{c}\text { Final } \\
\text { extension }\end{array}$ \\
\hline ceuE & $\begin{array}{c}94^{\circ} \mathrm{C} \\
5 \mathrm{~min} .\end{array}$ & $\begin{array}{c}94^{\circ} \mathrm{C} \\
30 \mathrm{sec} .\end{array}$ & $\begin{array}{c}55^{\circ} \mathrm{C} \\
40 \mathrm{sec} .\end{array}$ & $\begin{array}{c}72^{\circ} \mathrm{C} \\
45 \mathrm{sec} .\end{array}$ & 35 & $72^{\circ} \mathrm{C}$ \\
$10 \mathrm{~min}$.
\end{tabular}


Table (5) Percentage of C.coli and C. jejuni isolated from broiler and human fecal samples

\begin{tabular}{|c|c|c|c|c|c|}
\hline \multirow{2}{*}{ Samples } & No. of & \multicolumn{2}{|c|}{ C. coli } & \multicolumn{2}{c|}{ C. jejuni } \\
\cline { 3 - 6 } & samples & No. & \% & No. & \% \\
\hline Boiler & 50 & 43 & 86 & 7 & 14 \\
\hline Human & 50 & 33 & 66 & 17 & 34 \\
\hline Total & 100 & 76 & 76 & 24 & 24 \\
\hline
\end{tabular}

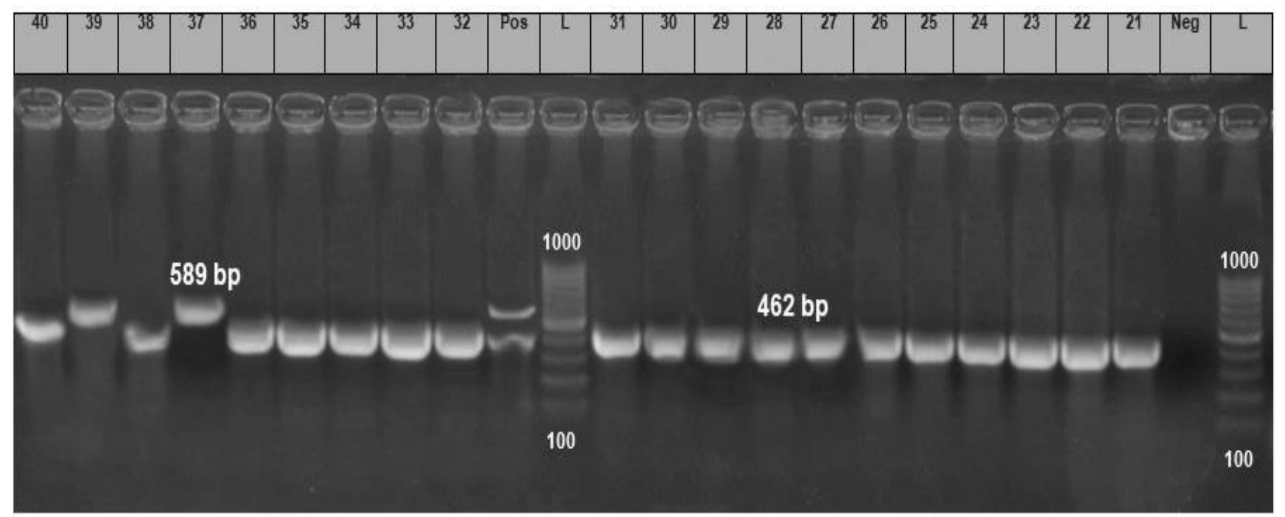

Photo (1): Agarose gel electrophoresis of 20 Campylobacter spp. isolated from broiler fecal samples for detection of mapA gene at 589 bp fragment and ceuE gene at $462 \mathrm{bp}$ fragment. L: 100-1000 bp. Pos: positive control $(C$. jejuni and C.coli strains identified by RLQP). Neg: negative control (Master Mix without DNA). Lanes (from 21to 36, 38 and 40) positive for C. coli. Lanes (37 and 39) positive for C. jejuni.

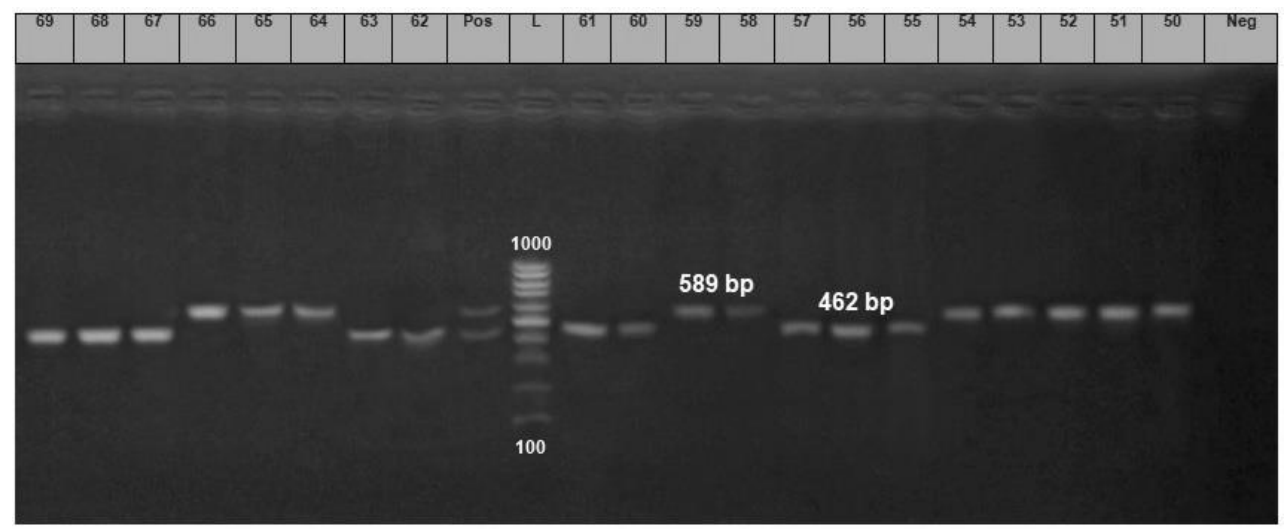

Photo (2): Agarose gel electrophoresis of 20 Campylobacter spp. isolated from human fecal samples for detection of mapA gene at $589 \mathrm{bp}$ fragment and ceuE gene at 462 bp fragment. L:100-1000 bp. Pos: positive control $(C$. jejuni and $C$. coli strains identified by RLQP). Neg: negative control (Master Mix without DNA). Lanes (from 50 to $54,58,59$ and from 64 to 66) positive 
for $C$. jejuni. Lanes (from55 to 57, 60, 63 and from 67 to 69) positive for $C$. coli.

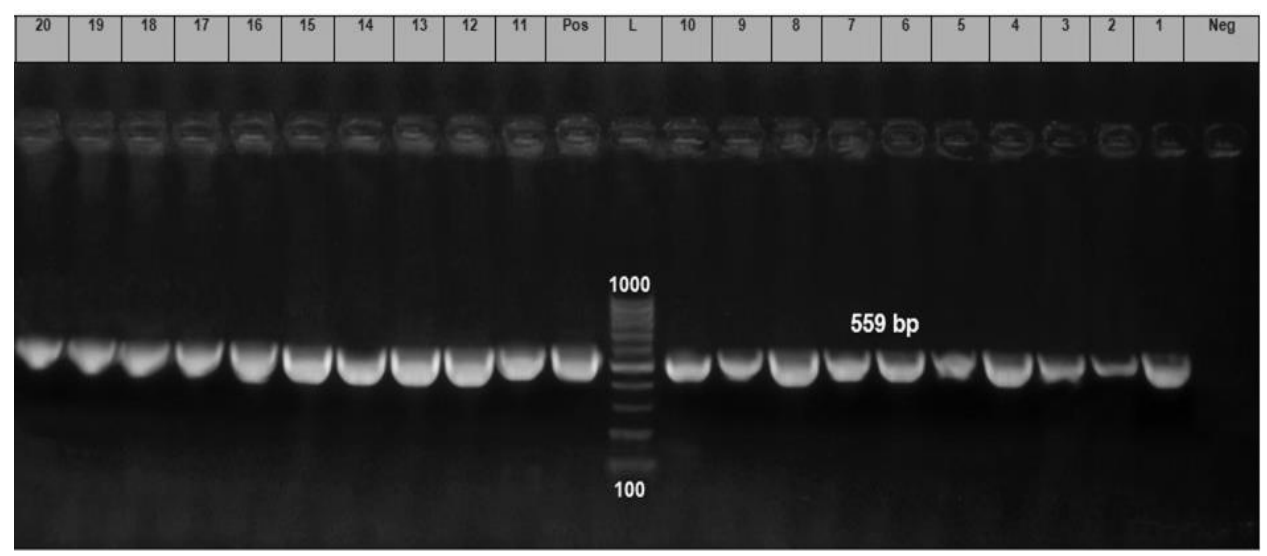

Photo (3): Agarose gel electrophoresis of 20 strains from C.coli and C. jejuni (10 for each) isolated from broiler and human fecal samples for detection of TetO gene for tetracycline resistance gene at $559 \mathrm{bp}$ fragment. L: 100-1000 bp. Pos: positive control. (Campylobacter carrying TetO gene). Neg: negative control (Master Mix without DNA).

\section{Discussion:}

Results shown in Table (5) revealed that the percentage of $C$. jejuni isolated from broiler fecal samples was $14 \%$ while $C$. coli was $86 \%$. These results nearly similar (Carreira et al., 2012) who obtained Campylobacter isolates with a percentage $83.3 \%$ in mainland Portugal, with a higher prevalence of C.coli $(61.2 \%)$ than C. jejuni (38.8\%). In Egypt (Sayed, 2000) examined 254 birds (190 visceral samples and 64 cecal swabs) on 4 broiler farms in for Campylobacter spp. and he found that $44(23.1 \%)$ of visceral samples and $12(18.7 \%)$ of cecal swabs were positive for Campylobacter spp. $C$. jejuni and $C$. coli were isolated from visceral samples and cecal swabs at the rate of $(20.5 \%, 15.6 \%)$ and $(2.6 \%, 3.1 \%)$ respectively. Of all isolates, $19.2 \%$ were $C$. jejuni and $2.7 \%$ were $C$. coli

Results discussed that isolation of both $C$. coli and $C$. jejuni from human fecal samples were $66 \%$ and $34 \%$ respectively, agreed with that obtained by (Butzler, 2004) who reported that cases of human campylobacteriosis represent only a small fraction of the actual number. Acute self-limited gastrointestinal illness, characterized by diarrhea, fever and abdominal cramps, is the most common presentation of $C$. jejuni and $C$. coli infection. (Nachamkin et al., 2000) stated that C. jejuni is now the most widely recognized antecedent cause of Guillain-Barre' syndrome, an acute paralytic disease of the peripheral nervous system. 
Regarding to, tetracycline resistant Campylobacter strains as shown in Photo (3). Which illustrated that all 20 randomly collected campylobacter strains were completely resistant to tetracycline as that all strains exhibited $\mathrm{TetO}$ gene. These findings agreed with (Wardak, 2005) who recorded that all isolated strains from Campylobacter showed high resistance to ciprofloxacin and erythromycin, while about $67 \%$ showed resistance to tetracycline, this is may occur due to mutation of gyrA protein gene (Charvalos et al., 1996). Tetracycline resistance has been reported due to presence of TetO gene. C. jejuni fluoroquinolone resistant strains reported in Europe, Asia, and USA.

\section{References:}

Bernadette, G. G., Essoh, A. E., Solange, K.G.E., Natalie, G., Souleymane, B., Ebastien, N. E. and Mireille, D. (2012): Prevalence and antimicrobial resistance of Thermophilic Campylobacter isolated from Chicken in Cote d'Ivoire. Inter. J. of Microbiol.V. 2012, Article ID 150612, 5 pages

Butzler, J.P. (2004): Campylobacter, from obscurity to celebrity. Clinical Microbiology and Infection, Volume 10, Issue 10, 2004: 868-876, https://doi.org/10.1111/j.14690691.2004.00983.x.

Burgos, C. V.; Wautier, M.; Martiny, D.; Cisneros, M.; Van
Damme, I. and De Zutter, L. (2017): Prevalence, antimicrobial resistance and genetic diversity of Campylobacter coli and Campylobacter jejuni in Ecuadorian broilers at slaughter age. Poultry Science 96:2366-2374.

Carreira, A. C., Clemente, L., Rocha, T., Tavares, A., Geraldes, M., Barahna, M., Botelho, J. and Cunha, M.V. (2012): Comparative Genotypic and Antimicrobial Susceptibility Analysis of Zoonotic Campylobacter Species Isolated from Broilers in a Nationwide Survey, Portugal. Journal of Food Protection: December 2012, Vol. 75, No. 12 , pp. 2100-2109

CDC (The US Center of Disease Control and prevention) (2013): Chapter 3 Infectious Diseases Related to Travel campylobacteriosis. Centers for Disease Control and Prevention 1600 Clifton Rd. Atlanta, GA 30333, USA.

Charvalos, E., Peteinaki, E., Spyridaki, I., Manetas, S. and Tselentis, Y. (1996): Detection of ciprofloxacin resistance mutations in Campylobacter jejuni gyrA by nonradioisotopic single-strand conformation polymorphism and direct DNA sequencing. J Clin Lab Anal.; 10:129-33.

Eunju, S. and Lee, Y. (2009): Comparison of Three Different Methods for Campylobacter Isolation from Porcine Intestines. J. Microbiol. Biotechnol., 19(7), 647650. 
Ezzat, M., Wahdan, A., Yousef, F. and Munier, M. (2018): Genetic variation of $\mathrm{E}$. coli strains isolated from poultry slaughterhouses at ismailia governorate, egypt." Adv. Anim. Vet. Sci 6(12): 531-536.

Gibreel, A., Tracz, D.M., Nonaka, L., Ngo, T.M., Connell, S.R. and Taylor, D.E. (2004): Incidence of antibiotic resistance in Campylobacter jejuniisolated in Alberta, Canada, from 1999 to 2002, with special reference to tet $(\mathrm{O})$-mediated tetracycline resistanceAntimicrob Agents Chemother., Sep;48(9):3442-50.

Nachamkin, I., Ung, H. and Li, M. (2002): Increasing fluoroquinolone resistance in Campylobacter jejuni, Pennsylvania, 2001. Emerging diseases, 8(12), 1501-3.

USA,1982infectious

Park, P. (2002): The physiology of Campylobacter species and its relevance to their role as foodborne pathogens. International Journal of Food Microbiology. 74: 177-188

Persson, S. and Olsen K. E P. (2005): Multiplex PCR for identification of Campylobacter coli and Campylobacter jejunifrom pure cultures and directly on stool samples. Journal of Medical Microbiology. 54: 1043-1047.

Sayed, A. M. (2000): Campylobacter infection in broiler chickens in Assiut. Assiut Veterinary Medical Journal 2000 Vol.42 No.84 pp.213-221 ref.22

Schwan, P. (2010): Prevalence and antibiotic resistance of Campylobacter spp. in poultry and raw meat in the Can Tho Province, Vietnam. Examensarbete. 2010; 49. ISSN 1652-8697. http://epsilon.slu.se.

Wardak, S., Szych, J and Cieślik, A. (2005): PCR-restriction fragment length polymorphism assay (PCR-RFLP) as an useful tool for detection of mutation in gyrA gene at 86-THR position associated with fluoroquinolone resistance in Campylobacter jejuni. Med Dosw Mikrobiol. 2005; 57:295-301.

WHO (2002): World Health organization. Department of communicable diseases surveillance and response.Woodhead publishing, CRC press. 565 p.World's Poult. Sci. J. 52:7-25, 84, 87, 90, 9 


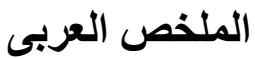

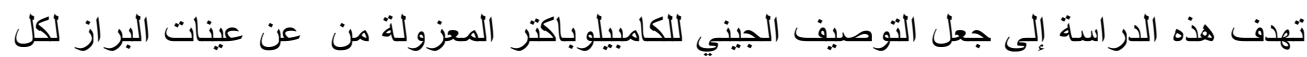

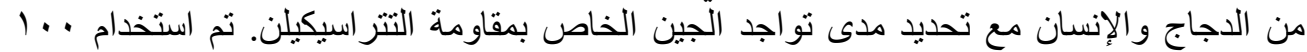

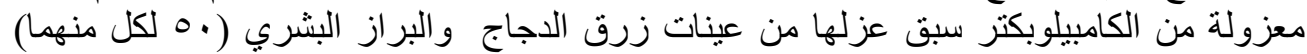

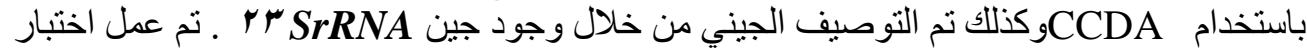

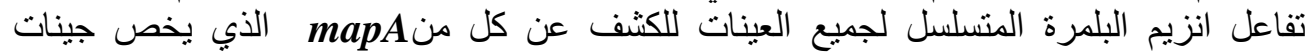

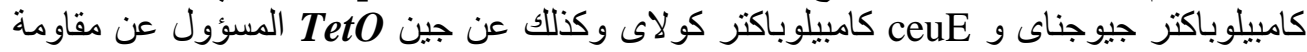

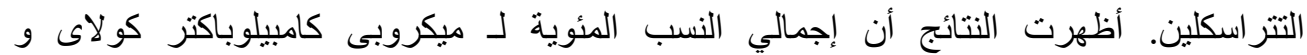

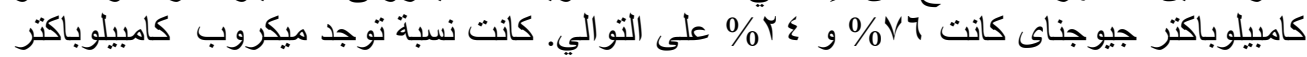

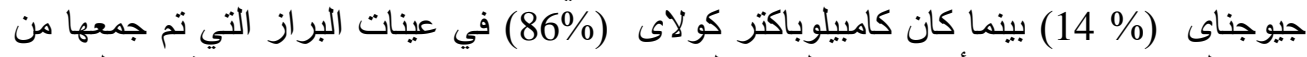

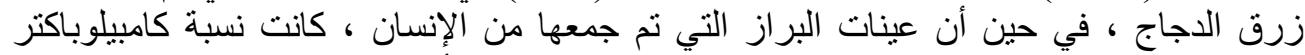

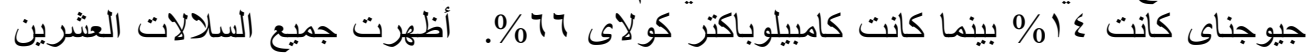

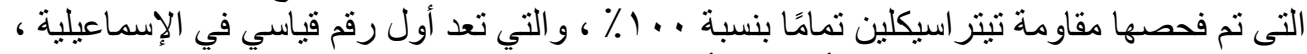

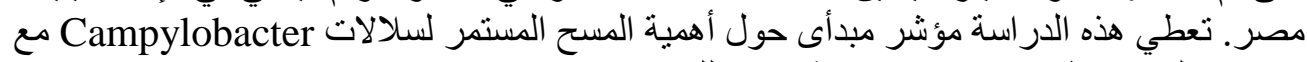
الاهتمام الكبير بتطوير سلالات مقاومة جديدة للميكروبات. 